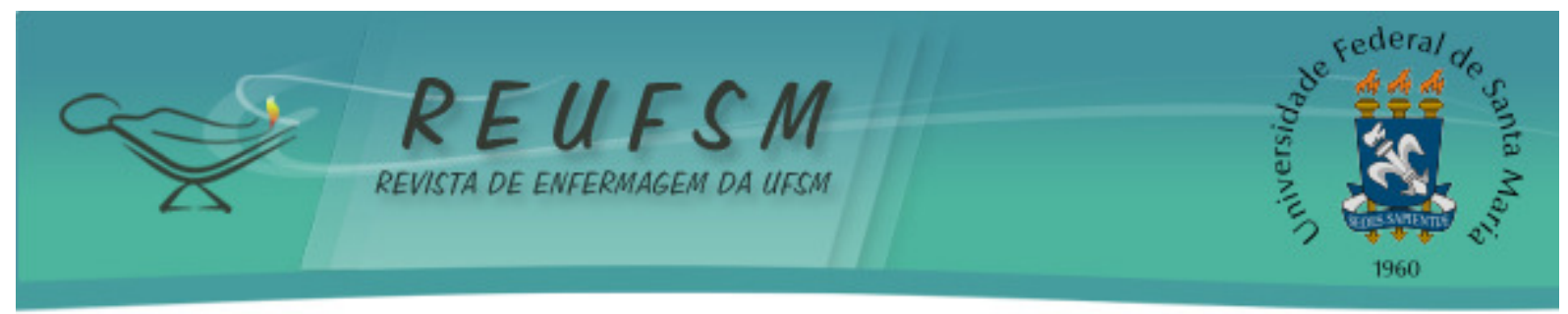

ARTIGO ORIGINAL

\title{
A PERCEPÇÃO DE FORMANDOS SOBRE A PESQUISA EM ENFERMAGEM NO CURSO DE GRADUAÇÃO ${ }^{1}$
}

\section{PERCEPTIONS OF SENIOR STUDENTS REGARDING RESEARCH IN NURSING AT THE UNDERGRADUATE COURSE}

\section{LA PERCEPCIÓN DE LOS ESTUDIANTES PRÓXIMOS A GRADUARSE SOBRE LA INVESTIGACIÓN EN ENFERMERÍA EN EL CURSO DE GRADUACIÓN}

\author{
Vanessa Cruz Santos ${ }^{2}$ \\ Karla Ferraz dos Anjos ${ }^{3}$ \\ Obertal da Silva Almeida ${ }^{4}$
}

RESUMO: Objetivo: investigar a percepção de formandos sobre a pesquisa em enfermagem no curso de graduação. Método: estudo qualitativo, com coleta de dados a partir de questionário aplicado a 81 formandos do curso de Enfermagem de uma Instituição de Ensino Superior de um município do interior baiano. A amostra foi probabilística aleatória simples. Para analisar os dados, utilizou-se a técnica de Análise de Conteúdo Temática. Estudo aprovado pelo Comitê de Ética em Pesquisa, sob Parecer $n^{\circ}$. 039/2009. Resultados: os formandos consideram haver deficit de metodologias de ensino e práticas pedagógicas de professores quanto ao incentivo à iniciação científica e à produção de pesquisas. Quase metade da amostra não realizou pesquisa durante a graduação e quase toda a amostra não publicou pesquisa. Conclusão: é necessário maior ênfase no educar em prol da pesquisa, para que o tripé ensino-pesquisa-extensão esteja presente na graduação de Enfermagem da instituição em estudo.

Descritores: Estudantes de enfermagem; Pesquisa em enfermagem; Educação em enfermagem.

\begin{abstract}
Objective: to investigate the perceptions of senior students about research in nursing at undergraduate level. Method: qualitative study, with data collected from a questionnaire applied to 81 senior students of the nursing course of a Higher Education Institution from a city of Bahia, Brazil. The sample was simple random probabilistic. Data was analyzed with the technique of Thematic Content Analysis. This study was approved by the Ethics in Research Committee - Report $n^{\circ}$ 039/2009. Results: the senior students consider that there are deficits on teaching methodologies and pedagogical practices of professors related to encouraging undergraduate scientific initiation and research production. Almost half of the sample did not conduct research during their studies, and almost the entire sample did not publish research. Conclusion: more emphasis is to be
\end{abstract}

\footnotetext{
${ }^{1}$ Artigo elaborado a partir do Trabalho de Conclusão do Curso de Bacharel em Enfermagem da Faculdade de Tecnologia e Ciências (FTC). Vitória da Conquista, BA, Brasil, 2010.

${ }^{2}$ Enfermeira. Mestranda pelo Programa de Pós-Graduação em Enfermagem e Saúde da Universidade Estadual do Sudoeste da Bahia (PPGES/UESB). Bolsista da Coordenação de Aperfeiçoamento de Pessoal de Nível Superior (CAPES). Membro do Grupo de Pesquisa Saúde e Qualidade de Vida da Universidade Estadual do Sudoeste da Bahia (UESB). Email: autoraautoria@hotmail.com

${ }^{3}$ Enfermeira. Mestranda pelo Programa de Pós-Graduação em Enfermagem e Saúde da Universidade Estadual do Sudoeste da Bahia (PPGES/UESB). Bolsista da Fundação de amparo à Pesquisa do Estado da Bahia (FAPESB). Membro do Grupo de Pesquisa Saúde e Qualidade de Vida da UESB. Email: Karla.ferraz@hotmail.com

${ }^{4}$ Biólogo. Mestre em Agronomia, área de concentração em Fitotecnia. Docente Assistente do Departamento de Estudos Básicos e Instrumentais da Universidade Estadual do Sudoeste da Bahia (UESB), Campus de Itapetinga, Bahia. Email: oalmeida@uesb.edu.br
} 


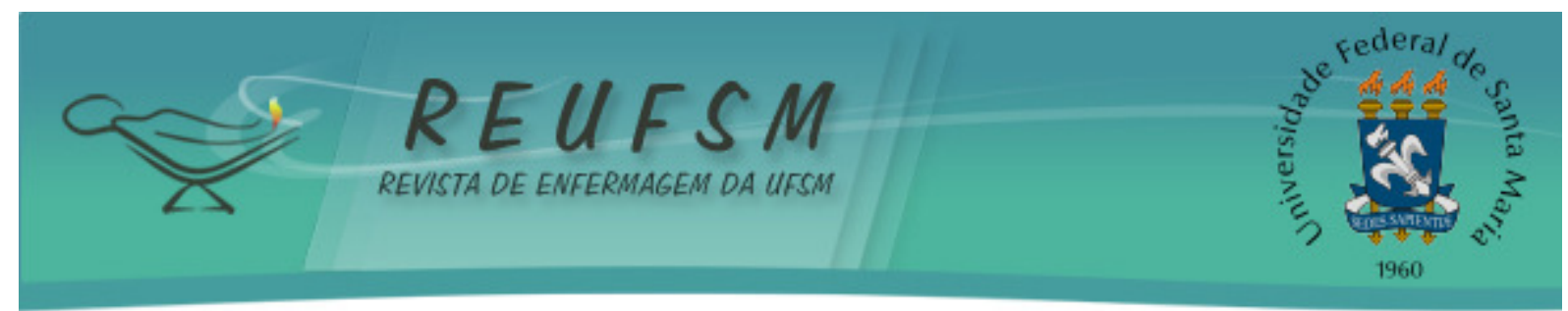

given on educating in favor of research, so that the tripod teaching-research-extension may be present in the studied Nursing Course's Institution.

Descriptors: Students, nursing; Nursing research; Education, nursing.

RESUMEN: Objetivo: investigar la percepción de los estudiantes próximos a graduarse sobre la investigación en enfermería en el Curso de Graduación. Método: estudio cualitativo, colecta de datos a partir de cuestionario aplicado con 81 académicos del curso de Enfermería de una Institución de Enseñanza Superior en Bahia, Brasil. La muestra fue probabilística aleatoria simple. El análisis de datos fue efectuado con la técnica del Análisis de Contenido Temático; Estudio aprobado por el Comité de Ética en Investigación - Parecer $n^{\circ}$. 039/2009. Resultados: los estudiantes consideran que hay déficit de enseñanza y prácticas pedagógicas cuanto al incentivo a la iniciación científica y a la producción de investigaciones. Casi la mitad de la muestra no realizó investigación durante la graduación, y casi toda la muestra no publicó investigación. Conclusión: es necesario mayor énfasis en educar para la investigación, para que el trípode enseñanzainvestigación-extensión esté presente en la graduación de Enfermería estudiada.

Descriptores: Estudiantes de enfermería; Investigación en enfermería; Educación en enfermería.

\section{INTRODUÇÃO}

A pesquisa na área da Enfermagem vem evoluindo em abrangência, pertinência e profundidade. Ao comparar a Enfermagem com outras áreas de conhecimento, verifica-se que ainda há a necessidade de se avançar em produções científicas qualificadas. Portanto, destaca-se a necessidade de estímulo à pesquisa, desde a formação do enfermeiro, fornecendo-se, assim, subsídios e visão crítico-reflexiva. ${ }^{1}$

Nesse sentido, torna-se justificável contextualizar este estudo, no qual tratar-se-á da iniciação científica na graduação em Enfermagem, que é capaz de estimular o aluno a aproximarse da realidade social, encorajando-o a desenvolver pesquisas ainda no meio acadêmico, contribuindo tanto para a formação profissional dos estudantes como para a evolução da ciência, tendo em vista a melhoria das condições de saúde e da qualidade de vida da sociedade.

Inserir o estudante de graduação na arte de pesquisar é o início da construção do ser pesquisador. Esta é uma prática também formadora, porém, é fundamental que o pesquisador em construção se reconheça como um aprendiz permanente e que, por meio do processo reflexivo, se mantenha em constante atualização para produção de conhecimento. ${ }^{2}$

Apesar de a pesquisa proporcionar novas descobertas aos alunos de graduação em Enfermagem, assim como contribuir na formação profissional e ética destes indivíduos, uma problemática vista em algumas Instituições de Ensino Superior (IES) do Brasil é o deficit na quantidade de alunos engajados com o desenvolver pesquisas. Vários destes alunos concluem o curso sem terem vivenciado esta experiência (a de pesquisar), que precisa ser prioridade nas propostas metodológicas de ensino das IES e nas práticas pedagógicas de professores, como algo relevante para viabilizar o tripé da educação ensino-pesquisa-extensão.

As pesquisas científicas assumem o lugar de inovação no processo educacional, assentando-se no desafio do aprender a aprender. Logo, as IES precisam se preocupar com o educar voltado para o conhecimento científico; e os discentes devem ser aguçados a realizar pesquisas científicas. Dessa forma, contribui-se tanto para a ciência quanto para a sociedade, compreendido cada ser como construtor e reconstrutor do meio em que vive. ${ }^{3}$

Diante da relevância da pesquisa na graduação, no sentido da formação ética e profissional do enfermeiro, surge a necessidade de responder à seguinte questão norteadora: qual a percepção de formandos sobre a pesquisa em enfermagem no curso de graduação? 


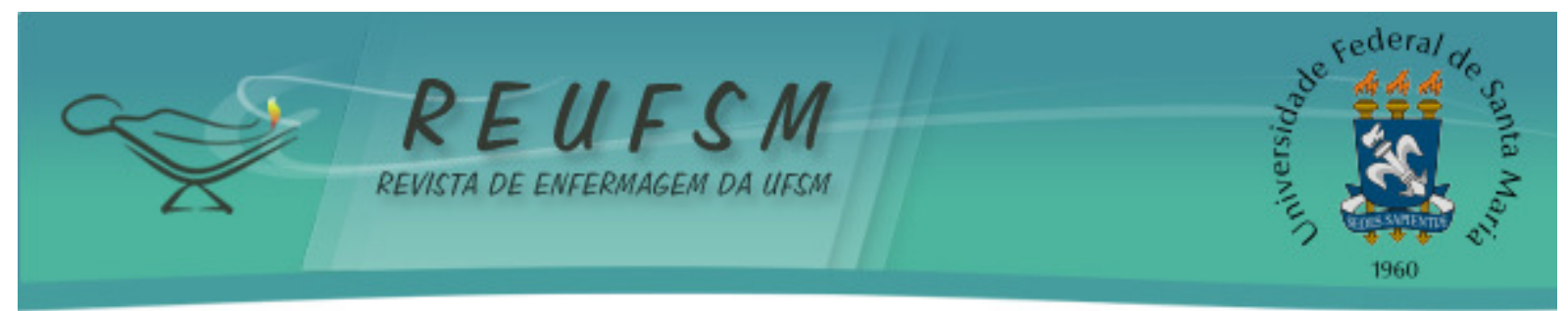

Dessa forma, o estudo tem como objetivo investigar a percepção de formandos sobre a pesquisa em enfermagem no curso de graduação.

\section{MÉTODO}

Trata-se de um estudo de abordagem qualitativa, realizado em uma Instituição de Ensino Superior privada, localizada em um município situado no interior do estado da Bahia, Região Nordeste do Brasil, tendo como população formandos do curso de Enfermagem, dos turnos matutino e vespertino, do sexo feminino e masculino, com idade igual ou superior a 18 anos.

Optou-se pela aplicação do questionário semiestruturado, que buscou enfatizar a pesquisa na graduação em Enfermagem. Os critérios de inclusão foram: serem formandos de Enfermagem, com idade igual ou superior a 18 anos, estarem matriculados regularmente e frequentando as aulas. A escolha pelos formandos deve-se ao fato de estes terem maior vivência e experiência como estudantes de ensino superior, e maior oportunidade de estarem engajados na iniciação científica e na produção de pesquisa.

Adotou-se como critérios de exclusão: serem acadêmicos de Enfermagem cursando semestre que não o último; formandos que não estavam presentes quando de três visitas da equipe organizadora deste estudo às salas de aula ou campo de estágio.

A coleta de dados foi realizada entre os dias 15 e 22 de fevereiro de 2010; os participantes foram escolhidos por meio de amostragem, da qual a população foi de 93 acadêmicos, sendo pesquisados 81 , com erro amostral de $4 \%$.

A amostra foi calculada conforme a seguinte fórmula: no $=1 / \mathrm{Eo}^{2} ; \mathrm{n}=\mathrm{N}$. no $/ \mathrm{N}$ + no. Temos que: $\mathrm{N}=$ tamanho (número de elementos) da população; $\mathrm{n}=$ tamanho (número de elementos) da amostra; no = uma primeira aproximação do tamanho da amostra; e Eo ${ }^{2}$ $=$ erro amostral tolerável. ${ }^{4}$

Foi utilizada a amostra probabilística aleatória simples, cuja principal característica é a realização de sorteio a partir de uma lista da população, da qual será escolhida a amostra desejada, sendo que cada elemento tem a mesma chance de ser sorteado. ${ }^{5}$

Para a análise dos dados, utilizou-se a técnica de Análise de Conteúdo Temática ${ }^{5}$, que se compõe de diferentes fases, que se organizam em três polos cronológicos a serem seguidos: a pré-análise, a exploração do material e o tratamento dos resultados. ${ }^{6}$

Inicialmente, na pré-análise, ocorreu a organização e a leitura completa do material digitado. Posteriormente, houve a releitura das respostas de cada questionário, registrando a frequência de surgimento das unidades de registro, para que fosse possível suscitar impressões e orientações de forma sistematizada.

Em seguida, na exploração do material, realizou-se leitura mais detalhada e exaustiva de cada resposta, observando, desta forma, o que surgia de mais significativo.

Por fim, foram feitos o tratamento dos resultados, a inferência e a interpretação, com a organização e a codificação do material, de maneira a serem significativos. Neste contexto, produziram-se uma classe temática, três categorias e nove subcategorias, que serão apresentadas em forma de tópicos.

Os participantes do estudo (formandos de Enfermagem) serão identificados por pseudônimos, a fim de preservar seu anonimato, sendo identificados pela vogal E seguida de algarismos arábicos.

A pesquisa ocorreu respeitando a Resolução n 196/96 do Conselho Nacional de Saúde, que estabelece as Diretrizes e Normas Regulamentadoras de Pesquisas envolvendo Seres Humanos. Os participantes manifestaram sua prévia aceitação, através da assinatura do Termo de Consentimento Livre e Esclarecido. Este estudo foi aprovado pelo Comitê de Ética em Pesquisa da Faculdade de Tecnologia e Ciências, sob o número 039/2009. 


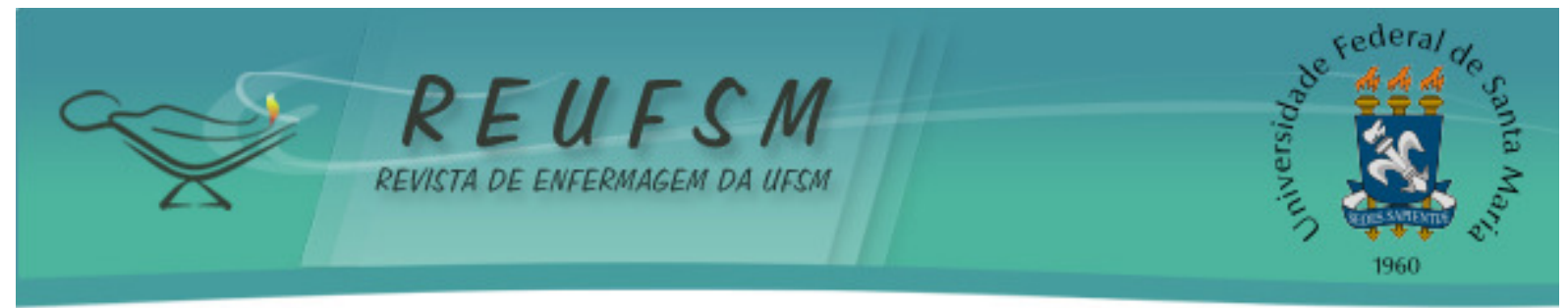

\section{RESULTADOS E DISCUSSÃO}

Dentre os 81 pesquisados, 35 têm idade de 18 a 23 anos, 26 têm de 24 a 29 anos, 12 têm entre 30 e 35 anos e oito têm acima de 36 anos. Quanto ao sexo, 13 são do sexo masculino e 68 do sexo feminino.

A partir da análise do conteúdo6 e dos resultados encontrados, foi possível dimensionar uma classe temática: pesquisa na graduação de enfermagem - agregada em categorias e subcategorias.

\section{Classe Temática: Pesquisa na graduação de Enfermagem}

Por meio da análise do material coletado, foram apreendidas respostas de formandos de Enfermagem quanto à pesquisa na graduação. Desta classe temática emergiram três categorias com oito subcategorias, totalizando 17 unidades temáticas.

\section{Categoria 01: Definição do que é pesquisa e a importância de sua realização na graduação de enfermagem}

Nesta categoria, foram agregadas unidades temáticas descritas por duas subcategorias, que foram extraídas a partir dos conteúdos das respostas dos questionários. Esta categoria traz a pesquisa científica ancorada em um processo metodológico que proporciona conhecimentos e possibilita possíveis soluções de problemas investigados, objetivada nas seguintes subcategorias: definição do que é pesquisa, contribuição da pesquisa em enfermagem na formação do graduando e dificuldades de formandos na realização e publicação de pesquisas.

\section{Definição do que é pesquisa}

Nesta subcategoria, foram apreendidas respostas dos participantes referentes ao significado do termo pesquisa. Entre os respondentes, verificou-se um conhecimento superficial, embora tenham suscitado elementos fundamentais que fazem parte do processo de pesquisa.

A pesquisa científica é um meio metodológico que permite ao pesquisador conhecer a realidade de uma população em foco [...] de forma que soluções sejam apresentadas ou então desperte uma visão crítica no pesquisador. (E7)

[...] trata-se de um estudo realizado com o objeto de pesquisa em que há investigação planejada, assim podendo encontrar possíveis soluções para determinado problema [...] a mesma gera conhecimentos até então implícitos e colabora para a coletividade. (E42)

\section{Contribuição da pesquisa em enfermagem na formação do graduando}

Analisando esta subcategoria, notou-se que, apesar de ser relevante a realização de pesquisa na área de Enfermagem, tanto para o crescimento da profissão como do indivíduo, vários formandos deste Curso discordam, por considerarem a Enfermagem uma profissão com autonomia insuficiente para a prática da pesquisa. 


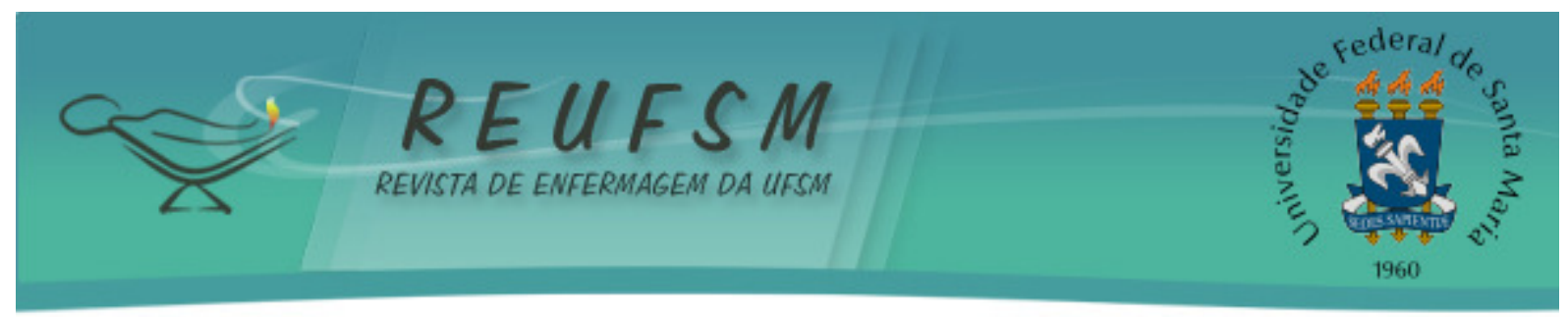

Não acho importante pesquisar, pois a enfermagem é tão submissa que a criação de algo, não será impactante para a sociedade. (E4)

A construção de conhecimentos advindos da pesquisa poderá contribuir para a formação de enfermeiros competentes no processo investigativo, favorecendo, assim, um cuidado mais qualificado. 0 desenvolvimento da pesquisa desde a graduação é uma relevante estratégia para formar profissionais qualificados. ${ }^{7}$ Apesar de a pesquisa na área de Enfermagem ser relevante, como aponta o autor acima, os resultados deste estudo indicam divergência por identificar que vários estudantes não concordam com essa ideia.

\section{Dificuldades de formandos na realização e publicação de pesquisas}

No que concerne a esta subcategoria, apenas um formando de Enfermagem refere ter publicado algum trabalho durante a graduação; a maioria não estava construindo trabalho, bem como não havia submetido nenhum para tentar publicá-lo, afirmando ter dificuldades.

Sinto dificuldade devido a falta de incentivo à iniciação científica pela faculdade em que estudo e burocracia das revistas quanto as normas. (E79)

Não consigo encontrar um professor disposto para me orientar e ajudar a desenvolver e publicar meus estudos, [...] alguns só têm interesse em se promover, apenas com seu nome no trabalho [...]. A faculdade não dá subsídio nem incentivo a iniciação cientifica [...].(E36)

Vários acadêmicos "escravizam" suas ideias, aprisionando o seu potencial de desbravador, e até mesmo de ser reconhecido pelos seus feitos, como foi evidenciado nos resultados deste estudo, uma vez que quase todos os pesquisados não tinham nenhum trabalho publicado durante a graduação.

Os estudantes que disseram ter dificuldades em publicar seus trabalhos sustentaram suas respostas relacionando, principalmente, o processo de avaliação e normas de revistas.

Penso que uma das maiores dificuldades do graduando publicar sua pesquisa está relacionado principalmente ao: status do corpo editorial quanto ao nível de titulação dos autores. (E44)

Déficit na explicitação de normas do periódico. (E52)

Demora de resposta pela revista, o que pode tornar o assunto em pauta desatualizado. (E33)

As dificuldades em publicar podem estar relacionadas às exigências dos periódicos. Referindo-se à taxa de aceitação de trabalhos pelas revistas, entre 2006 a 2009 , foi visto que cerca de $15 \%$ dos artigos submetidos nem retornaram com respostas para os autores, e apenas $1 \%$ foi aceito sem revisão. Além disso, $85 \%$ dos manuscritos submetidos são cortados pelo editor ou seus auxiliares diretos, e apenas $15 \%$ são submetidos à avaliação pelos referees. ${ }^{8}$ Essa informação corrobora com as respostas dos formandos de Enfermagem, que afirmaram encontrar dificuldade em publicar. 


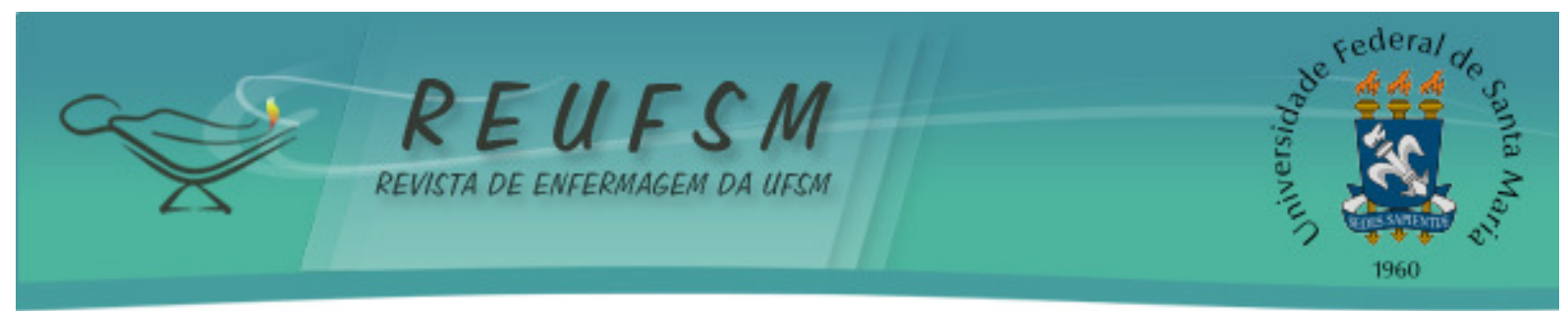

Categoria 02: A inclusão da pesquisa em enfermagem como estratégia de ensinoaprendizagem

A análise desta categoria traz a pesquisa como parte fundamental do processo ensino-aprendizado. Esta categoria se apresenta em unidades temáticas que estão apoiadas por três subcategorias: a pesquisa em enfermagem como estratégia metodológica de ensino, participação de formandos em grupos de pesquisa e obrigatoriedade e destino a ser dado ao Trabalho de Conclusão de Curso.

\section{A pesquisa em enfermagem como estratégia metodológica de ensino}

A análise desta subcategoria permite constatar que, apesar de a pesquisa científica ser parte fundamental do tripé ensino-pesquisa-extensão, a Instituição em estudo, especificamente no que se refere ao curso de Enfermagem, não adota de maneira satisfatória metodologias que incluam, de forma transversal, a realização de pesquisas como estratégia de ensino-aprendizagem, algo essencial para a formação pessoal e profissional do enfermeiro, assim como uma forma de proporcionar benefícios à sociedade.

A pesquisa é essencial para minha formação [...] na instituição não há metodologias de ensino capazes de abordar a pesquisa de forma transversal. (E44)

[...] os professores não ensinam pesquisar [...] não incentivam os alunos a realizarem pesquisas [...] como forma de avaliação da disciplina ou estágio, nem de incentivo ao nosso crescimento. (E14)

Educar em prol da pesquisa não é tarefa fácil, exige dedicação e responsabilidade do aluno e do professor. Quanto às IES, poucas fomentam a pesquisa e a extensão como parte fundamental do processo pedagógico. Porém, o ensino superior somente estará mais alicerçado quando o estudante tiver acesso à tríade ensino-pesquisa-extensão no decorrer da graduação. ${ }^{9}$

O tripé formado por ensino, pesquisa e extensão deve estar inserido no processo ensino-aprendizagem, conforme explícito no Artigo 207 da Constituição Federal de 1988, que dispõe que as universidades obedecerão ao princípio da indissociabilidade entre os elementos desse tripé. ${ }^{10}$

Educar indivíduos requer compromisso tanto da administração da instituição de ensino como dos professores para com cada aluno; por isso, as metodologias de ensino devem sofrer constantes transformações, adequando-se às necessidades contemporâneas de ensino-aprendizagem. ${ }^{11}$

Entre os métodos que podem ser utilizados no processo ensino-aprendizagem, a Prática Baseada em Evidência (PBE) se configura em um relevante instrumento na assistência à saúde, uma vez que é método sistematizado que possibilita agrupar, classificar e analisar resultados de pesquisas e concluir por evidências ou não para tomada de decisões por profissionais. ${ }^{12}$

Referindo-se, ainda, às respostas dos participantes da pesquisa no que se refere às metodologias que incluam a realização de pesquisas como estratégia de ensinoaprendizagem, percebe-se um desconexo em relação às metodologias adotadas pela IES em estudo, uma vez que ela não fomenta o tripé ensino-pesquisa-extensão como parte do processo ensino-aprendizagem. 


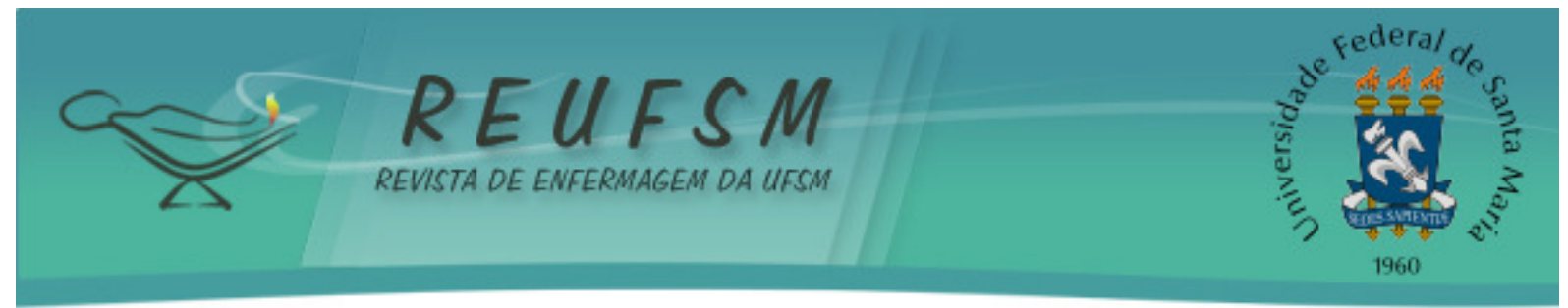

Participação de formandos em grupos de pesquisa

A partir desta subcategoria, foi possível identificar a participação dos formandos de Enfermagem em algum grupo de pesquisa; porém, todos afirmaram nunca terem sido membros de algum outro grupo antes, fundamentando suas respostas conforme evidenciado:

$\mathrm{Na}$ instituição em que estudo não tem grupos de pesquisa, em que os acadêmicos podem participar. (E65)

Sei que é relevante participar de grupo de pesquisa [...], até tentei ver a possibilidade em participar de algum, porém me informaram que na instituição que estudo não existia. (E10)

A participação de acadêmicos em grupos de pesquisa favorece uma visão ampliada do processo de pesquisa; no entanto, essa participação ainda é pequena em razão do processo estrutural de algumas instituições de ensino. ${ }^{13}$ Esse contexto corrobora com os resultados encontrados no presente estudo.

0 avanço científico e tecnológico da Enfermagem necessita da busca de novos talentos, o que pode ocorrer por meio dos grupos de pesquisa. ${ }^{7}$ A dinâmica de funcionamento desses grupos como espaço de relações, trocas e trabalho propicia ao graduando aprender a fazer pesquisa ou a ser pesquisador iniciante. ${ }^{2}$

No desenvolvimento dos projetos, o grupo de pesquisa foi citado como principal motivação para o aprendizado do estudante, na sua inserção e evolução enquanto pesquisador. ${ }^{2} \mathrm{O}$ que diverge dos resultados encontrados no presente estudo, uma vez que os formandos de Enfermagem aqui estudados não tiveram a oportunidade de participar desse tipo de atividade.

\section{Obrigatoriedade e destino a ser dado ao Trabalho de Conclusão de Curso}

Verificou-se, nesta subcategoria, que a confecção e apresentação do Trabalho de Conclusão de Curso (TCC) é obrigatória para obtenção do grau de bacharel em Enfermagem na Instituição em estudo. Todavia, a maioria dos formandos é contrária a esta obrigatoriedade, informando que o destino dado ao seu TCC não é a publicação - algo preocupante, uma vez que tornar públicos os resultados de uma pesquisa é fundamental para a evolução e consolidação da ciência, além de contribuir com a sociedade.

Meu TCC vai ficar na biblioteca da instituição de ensino e na unidade de pesquisa, conforme orientação do professor. (E79)

Com certeza meu trabalho vai ficar parado por aí, em alguma estante. (E46)

Acho que vou guardar meu TCC. (E1)

Vou engavetar, pois não recebi incentivo e orientação da instituição para aprimorar o trabalho e torná-lo público. (E71)

Diante dos resultados, é preciso refletir que vários estudantes deixariam de elaborar e sustentar seu TCC se este não fosse obrigatório. Além disso, é válido enfatizar 


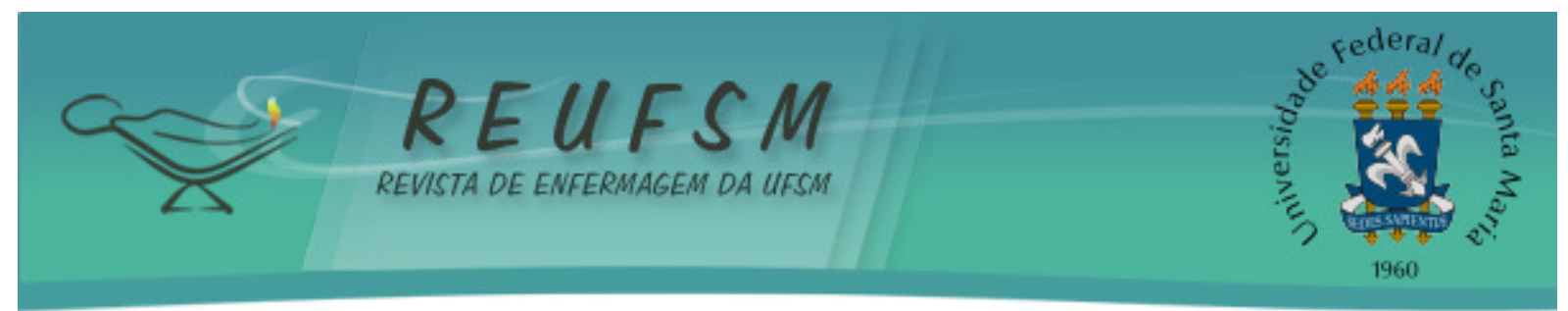

que tão importante quanto à construção do TCC é a sua publicação, o que não ocorrerá com a maioria dos TCC que foram realizados pelos formandos de Enfermagem em estudo.

O TCC é uma atividade obrigatória em diversas IES do Brasil, e dentre seus objetivos estão os de desenvolver a capacidade dos discentes, estimulando sua competência, incentivando o interesse pela pesquisa e o espírito empreendedor e crítico-reflexivo. ${ }^{14}$ Mesmo estando evidenciada a importância do TCC na academia, a maior parte dos formandos não aceita que esta seja uma atividade obrigatória, como explicitado no contexto acima.

\section{Categoria 03: Contribuições das pesquisas produzidas na graduação de enfermagem para a ciência e sociedade}

O desvelar desta categoria mostra como os informantes percebem a importância do incentivo, tanto da instituição de ensino quanto do corpo docente, à realização de pesquisas, com o intuito de contribuir para a ciência e para a sociedade. Desta categoria emergem duas subcategorias: formandos que acreditam poder contribuir para a ciência e sociedade a partir de suas pesquisas e formandos que acreditam não poder contribuir para a ciência e sociedade a partir de suas pesquisas.

Formandos que acreditam poder contribuir para a ciência e sociedade a partir de suas pesquisas

A partir desta subcategoria, nota-se que, mesmo diante do relato dos formandos de Enfermagem, sobre o deficit de incentivo para a realização de pesquisas, no decorrer do Curso, existem alguns que acreditam na possibilidade de contribuir para com a ciência e com a sociedade a partir de suas pesquisas.

Mesmo que na instituição que estudo não existe incentivo a iniciação científica, o pouco que aprendo nas disciplinas de metodologia me ajuda a desenvolver pesquisas, publicá-las, contribuir para a evolução científica e ajudar a sociedade superar seus problemas. (E80)

Tomando como referência os depoimentos dos participantes, observa-se que, mesmo sendo minoria, vários formandos do curso de Enfermagem acreditam que, por meio das pesquisas realizadas na graduação, é possível colaborarem com a ciência e, por conseguinte, ajudarem na promoção e na prevenção de agravos à saúde, melhorarem a qualidade da atenção e dos cuidados prestados, e contribuírem na superação de problemas enfrentados pela sociedade.

As pesquisas científicas produzidas no meio acadêmico devem objetivar a extensão dos seus resultados para a sociedade, podendo transformar a própria IES em um espaço enraizado na comunidade; sendo assim, o conhecimento teria como finalidade contribuir para a concretização das demandas do bem público. ${ }^{15}$ Tal pensamento se assemelha com o de alguns formandos que acreditam na potencialidade das pesquisas para beneficiar a sociedade.

Formandos que acreditam não poder contribuir para a ciência e sociedade a partir de suas pesquisas

Esta subcategoria revela que a maioria dos formandos informou não serem capazes de contribuir para a ciência e para a sociedade a partir de suas pesquisas, e suas respostas enfatizam insatisfação na área da Enfermagem e deficit de incentivo para pesquisar. 


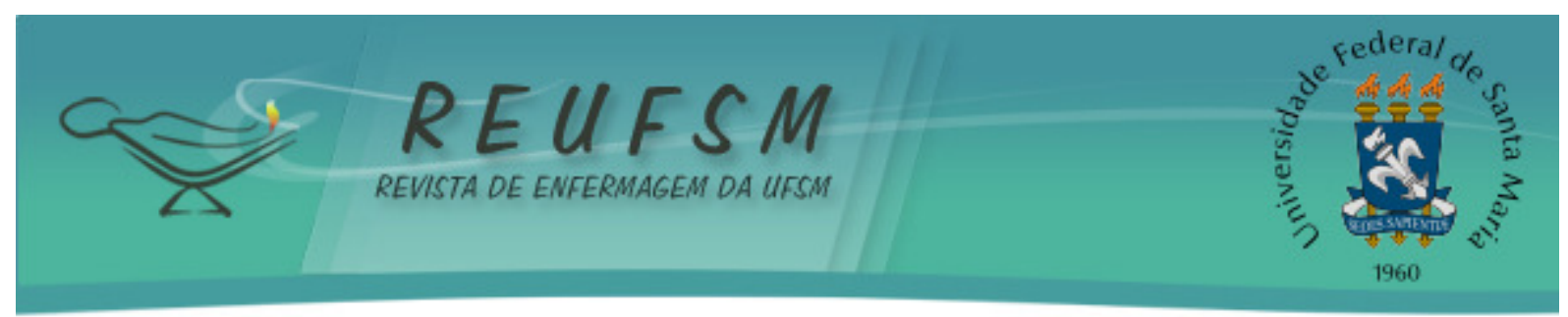

Não posso nem pretendo contribuir com a ciência [...], logo vou sair da área da saúde e não quero seguir algo que não me dê uma renumeração e um status de valor. (E66)

Não sei fazer pesquisa [...] e na academia o diretor acadêmico e os professores não incentivam [...], muito deles também não sabem [...]. (E15)

Ainda relacionado a esta subcategoria, notou-se que a maior parte dos formandos revelou que o incentivo oferecido pela Instituição em que estudam não é suficiente para contribuir com o crescimento do aluno em desenvolver pesquisas. Mesmo sabendo da importância destas, não se sentem capazes de contribuir para a ciência e a sociedade por meio da pesquisa.

Como nós acadêmicos podemos contribuir com a ciência se a própria instituição em que estudamos não nos apóia? [...] Sei que por meio da pesquisa poderia ajudar a ciência nos seus obstáculos [...], mas onde estudo, a direção e muitos professores são descomprometidos com a iniciação científica [...] esquecem que a pesquisa caminha junto a educação e a ciência. (E29)

Formar alunos com espírito científico requer criar condições favoráveis desde o seu ingresso até o último ano no curso, promovendo o desenvolvimento de suas habilidades e competências investigativas em temas transversais. A pesquisa na academia tem sido dificultada devido ao deficit de incentivo no processo ensino-aprendizagem e a qualificação de professores, um entrave à motivação de alunos. ${ }^{16}$ Os resultados do presente estudo são divergentes com a contextualização deste autor, uma vez que vários estudantes dizem haver deficit de incentivo da Instituição em que estudam quanto à realização de pesquisa e seu poder de contribuição em diversos segmentos.

A produção e a socialização de conhecimentos vêm sendo alvo de amplos interesses e desafios. ${ }^{17}$ A pesquisa na área da Enfermagem, como nas demais áreas, é essencial para absorver, produzir, aperfeiçoar e reproduzir conhecimento, visando à melhoria da qualidade de vida dos indivíduos e do desenvolvimento científico e tecnológico. ${ }^{2}$

Para que ocorra o fortalecimento da educação em Enfermagem, é preciso haver integração de interesses com propósitos solidários. A necessidade contemporânea é de que se estabeleçam parcerias entre diversos departamentos e áreas de conhecimento, fortalecendo, assim, a criação de redes e pesquisas de caráter multicêntrico, com várias lideranças e possibilidades de articulação político-científica. ${ }^{18}$

\section{CONSIDERAÇÕES FINAIS}

Este estudo permitiu investigar a percepção de formandos sobre a pesquisa em enfermagem no curso de graduação. Apesar da relevância das contribuições advindas desta pesquisa, notou-se que a IES em estudo utiliza pouco desta estratégia capaz de contribuir para a formação pessoal e profissional, assim como para a melhoria nas condições de saúde da sociedade.

É merecido salientar a necessidade de uma sustentável base metodológica que incentive a prática científica como um instrumento estritamente entrelaçado ao processo de formação ética e profissional dos graduandos. A IES em estudo deveria implementar a iniciação científica como uma prioridade para a viabilização do tripé pesquisa-ensino- 


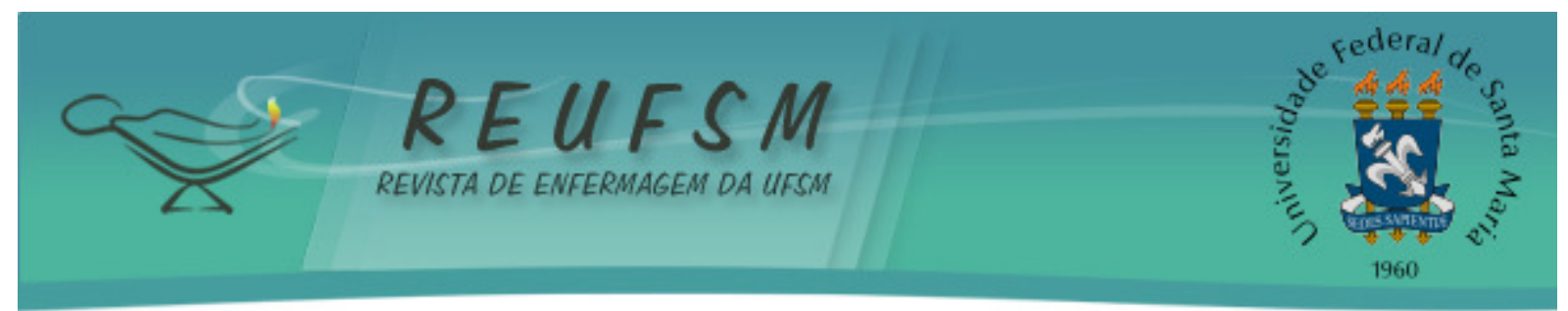

extensão. Porém, conforme os resultados deste estudo, a maioria dos formandos de Enfermagem da referida IES considera haver deficit de metodologias de ensino voltadas para o incentivo à iniciação científica e a produção de pesquisas, em sua Instituição de ensino e em práticas pedagógicas de professores.

Enfim, são necessárias mudanças na formação acadêmica dos graduandos da IES em estudo, partindo do pressuposto de que esta Instituição precisa substituir algumas de suas metodologias de ensino, que muitas vezes não engajam os discentes na iniciação científica, por propostas mais dinâmicas, formadoras de indivíduos capazes de construir, reconstruir, pesquisar e expandir seus conhecimentos, propiciando benefícios à sociedade.

Ressalta-se que, dentre as limitações deste estudo, pode ser citado o uso do questionário semiestruturado, o que não permitiu maior aprofundamento dos dados, além da escassez de estudos que abordassem a pesquisa na graduação a partir de formandos de Enfermagem, o que dificultou a comparação deste estudo com outros.

Apesar das limitações, este estudo poderá estimular docentes e IES na discussão acerca da relevância da iniciação científica como parte indispensável no processo ensinoaprendizagem de estudantes de Enfermagem, uma vez que esta é um subsídio para a realização de pesquisas na graduação.

\section{REFERÊNCIAS}

1. Erdmann AL. A necessidade de atingirmos novos patamares na pesquisa em enfermagem. Acta Paul Enferm. 2009;22(2):5-6.

2. Erdmann AL, Leite JL, Nascimento KC, Lanzoni GMM. Vislumbrando o significado da iniciação científica a partir do graduando de enfermagem. Esc Anna Nery Rev Enferm. 2010 mar;14(1):26-32.

3. Furlan F, Nascimento FR. A pesquisa e o professor: desafio atual da educação [Internet]. 2009 [acesso em 2010 dez 18]. Disponível em: http://www.unifra.br/eventos/jornadaeducacao2006/2006/pdf/artigos/pedagogia/A\%20P ESQUISA\%20E\%200\%20PROFESSOR.pdf.

4. Barbetta PA. Estatísticas aplicadas às ciências sociais. $7^{\text {a }}$ ed. Florianópolis (SC): FAPEU UFSC; 2007.

5. Dyniewicz AM. Metodologia da pesquisa em saúde para iniciantes. $2^{a}$ ed. São Paulo (SP): Difusão; 2009.

6. Bardin L. Análise de conteúdo. Lisboa: Edições 70; 2011.

7. Erdmann AL. Formação de especialistas, mestres e doutores em enfermagem: avanços e perspectivas. Acta Paul Enferm. 2009;22(Esp-Nefrologia):551-3.

8. Oliveira ACO, Almeida FN, Rebouças JTS, Silva HIS, Faria TSM, Cipola Neto J, et al. Papel da publicação científica na carreira acadêmica: relatório do debate 05/05/2009. Debates Atuais em Ciências Biomédicas [Internet]. 2009 [acesso em 2010 fev 16]. Disponível

em:

http://www.fisio.icb.usp.br/aulasfisio/disciplinas/bmb5805/RelatorioDebateV2.pdf.

9. Silva PP. A efetivação do princípio da indissociabilidade: um desafio para a Educação Superior. Ciência \& Desenvolvimento. 2008;1(1):45-9.

10. Moita FMGSC, Andrade FCB. Ensino-pesquisa-extensão: um exercício de indissociabilidade na pós-graduação. Rev Bras Educ. 2009;14(41):269-393. 
11. Anjos KF, Santos VC, Almeida OS. Vivendo na era das inovacões: perspectivas epistemológicas emergentes na formação de profissionais da enfermagem. REUOL [Internet]. 2011 set [acesso em 2011 out 1];5(7):1759-67. Disponível em:

http://www.revista.ufpe.br/revistaenfermagem/index.php/revista/article/view/1818/pdf _627 doi:10.5205/reuol.1262-12560-1-LE.0507201126.

12. Lacerda RA, Nunes BK, Batista AO, Egry EY, Graziano KU, Angelo M, Merighi, MAB, et al. Práticas baseadas em evidências publicadas no Brasil: identificação e análise de suas vertentes e abordagens metodológicas. Rev Esc Enferm USP. 2011 jun;45(3):777-86.

13. Krahll M, Sobiesiakl EF, Polettol DS, Casarinl RG, KnopfI LA, Carvalhol J, et al. Experiência dos acadêmicos de enfermagem em um grupo de pesquisa. Rev Bras Enferm. 2009;62(1):146-50.

14. Ministério da Educação (Brasil). Regulamento do Trabalho de Conclusão de Curso (TCC) para os cursos de graduação da UTFPR Curitiba: Resolução no 120/06 - COEPP, de 07 de dezembro de 2006. Universidade Tecnológica Federal do Paraná [Internet]; 2006 [acesso em 2010 fev 23]. Disponível em: http://www.ap.utfpr.edu.br/download/Regulamentos/Regulamento_TCC.pdf

15. Gouvêa F. "Dr. Anísio, ele pensava e executava": a trajetória de Anísio Teixeira no campo da formação de professores no Brasil (1924-1950). Rev Contemporânea de Educação. 2009;4(8):431-47.

16. Palmeira IP, Rodriguéz MB. A investigação científica no curso de enfermagem: uma análise crítica. Esc Anna Nery Rev Enferm. 2008;12(1):68-75.

17. Erdmann AL. A importância da publicação científica. Editorial. Rev Enferm UFSM [Internet]. 2011 maio/ago [acesso em 2010 fev 16];1(2). Disponível em: http://cascavel.ufsm.br/revistas/ojs-

2.2.2/index.php/reufsm/article/download/2995/1688.

18. Lino MM, Backes VMS, Canever BP, Ferraz F, Prado ML. Profile of scientific and technological production in nursing education research groups in the south of Brazil. Rev Latinoam Enferm. 2010;18(3):452-8.

Data de recebimento: $26 / 01 / 2013$

Data de aceite: 23/05/2013

Contato com autora responsável: Vanessa Cruz Santos

Universidade Estadual do Sudoeste da Bahia/Programa de Pós-Graduação em Enfermagem e Saúde.

Endereço Postal: Avenida José Moreira Sobrinho, s/n, Jequiezinho, Jequié, BA, Brasil.

CEP: 45206-190

E-mail: autoraautoria@hotmail.com 